\title{
Berberine induces lipolysis in porcine adipocytes by activating the AMP-activated protein kinase pathway
}

\author{
YONGQING YANG*, RONGSHENG LU*, FANGFANG GAO*, JIE ZHANG and FENGLAN LIU \\ Department of Biological Science, College of Life Science, Shanxi Normal University, Linfen, Shanxi 041000, P.R. China
}

Received June 06, 2019; Accepted March 17, 2020

DOI: $10.3892 / \mathrm{mmr} .2020 .11070$

\begin{abstract}
Lipolysis is closely associated with obesity and insulin resistance. Berberine (BBR), a natural alkaloid derived from Coptis chinensis, has been shown to regulate lipolysis and improve insulin resistance. However, the underlying mechanism remains unclear. The present results suggested that BBR stimulated lipolysis in porcine adipocytes in a dose- and time-dependent manner, which was independent of the cAMP/protein kinase A pathway. Further experimental results indicated that $\mathrm{BBR}$ increased phosphorylation levels of AMP-activated protein kinase (AMPK) and adipose triglyceride lipase (ATGL), along with downregulation of Perilipin A. The AMPK inhibitor compound C significantly reversed the effect of BBR on lipolysis, Perilipin A expression and ATGL phosphorylation. Furthermore, BBR promoted expression levels of genes related to fatty acid oxidation, such as peroxisome proliferator-activated receptor $\gamma$ coactivator-1 $\alpha$, mitochondrial transcription factor A, carnitine palmitoyl-transferase-1 and uncoupling protein 2, which were abrogated by AMPK $\alpha 1$ knockdown. Moreover, it was found that BBR-induced lipolysis did not elevate serine phosphorylation of insulin receptor substrate-1 to block insulin signaling. Collectively, the present results suggested that BBR induced lipolysis in porcine adipocytes via a pathway that involves AMPK activation, but does not cause insulin resistance.
\end{abstract}

Correspondence to: Dr Yongqing Yang, Department of Biological Science, College of Life Science, Shanxi Normal University, 1 Gongyuan Road, Linfen, Shanxi 041000, P.R. China

E-mail: yyqing71@163.com

*Contributed equally

Abbreviations: AMPK $\alpha$, AMP-activated protein kinase $\alpha$; ATGL, adipose triglyceride lipase; BBR, berberine; CPT-1, carnitine palmitoyl-transferase-1; DG, diglyceride; FA, fatty acids; FFAs, free fatty acids; HSL, hormone sensitive lipase; IRS-1, insulin receptor substrate-1; PGC-1 $\alpha$, peroxisome proliferator-activated receptor $\gamma$ coactivator- $1 \alpha$; TFAM, mitochondrial transcription factor A; TG, triglyceride; UCP2, uncoupling protein 2

Key words: berberine, lipolysis, adipocytes, AMPK pathway, fatty acid oxidation

\section{Introduction}

Obesity is characterized by excessive triglyceride (TG) stored in white adipocytes. There are two major types of adipose tissue with distinct functions in mammals, white adipose tissue (WAT) and brown adipose tissue (BAT). Of these, BAT is less abundant and specializes in non-shivering thermogenesis via mitochondrial lipid oxidation. However, WAT is primarily responsible for lipid storage, mostly of TG and participates in lipid metabolism (1). WAT in the body is broadly classified into subcutaneous and visceral fat depots, and is recognized as a versatile endocrine organ that produces a variety of adipokines, which can influence nutrient metabolism and immune responses. Moreover, visceral WAT secretes higher levels of inflammatory cytokines compared with subcutaneous WAT and is more likely to cause metabolic disorders (2). Therefore, WAT is the main adipose tissue involved in obesity and associated metabolic alterations.

Enzymatic hydrolysis of TG in adipocytes is a highly regulated process, which releases glycerol and free fatty acids (FFAs) in response to stimulation of certain hormones, cytokines or drugs, accompanied by activation of related signaling pathways. Adipose triglyceride lipase (ATGL) and hormone-sensitive lipase (HSL) are two rate-limiting enzymes that control the hydrolysis of TG $(3,4)$. Furthermore, released FFAs from adipocytes lipolysis can be used for thermogenesis in adipose tissue via $\beta$-oxidation and mitochondrial uncoupling, or is transported to peripheral tissues to provide energy (5). FFAs also function as modulators of glucose and insulin action (6), and insulin secretion (7). The elevation of plasma FFA levels is the result of increased fat mobilization and is thought to be associated with insulin resistance and type 2 diabetes (8). Moreover, sustained high FFAs in pancreatic $\beta$ cells may impair insulin secretion (9). Thus, the regulation of adipocytes lipolysis is vital to energy homeostasis, body fat controlling and metabolic health.

Berberine (BBR), a natural isoquinoline alkaloid derived from the Chinese herb Coptis chinensis, has been shown to have anti-obesity, antidiabetic, antihyperlipidemia and anti-inflammatory effects (10). Previous studies have mainly focused on the effect of BBR on lipogenesis and have primarily involved the use of mice and 3T3-L1 adipocytes (11-13). A limited number of studies have investigated the role of BBR in adipocyte lipolysis. It has been reported that BBR attenuates catecholamines-stimulated lipolysis in 3T3-L1 adipocytes 
via reducing the inhibition of phosphodiesterase $3 \mathrm{~B}$ and 4 , which are two enzymes involved in decreasing intracellular cAMP production (14). Furthermore, Jiang et al (15) revealed that BBR stimulated basal lipolysis in mature 3T3-L1 adipocytes by upregulating ATGL and inactivating HSL via the AMP-activated protein kinase (AMPK) pathway. Therefore, it was hypothesized that the different effects of BBR on adipocytes lipolysis may be attributed to different types or states of the cells; however, the precise mechanism by which BBR regulates lipolysis in adipocytes is not fully understood.

AMPK is a heterotrimeric serine/threonine protein kinase, composed of a catalytic $\alpha$ subunit and regulatory $\beta$ and $\gamma$ subunits. Moreover, two isoforms of the catalytic subunit have been identified as $\alpha 1$ and $\alpha 2$ (16). Threonine phosphorylation of $\mathrm{AMPK} \alpha$ is required for activation of AMPK and its downstream signaling cascades. Furthermore, AMPK is thought to act as a crucial cellular energy sensor that maintains energy homeostasis by regulating glucose and lipid metabolism (17). However, the role of AMPK in lipolysis in adipose tissue has been controversial. It was revealed that AMPK activation inhibits basal and isoproterenol-stimulated lipolysis in homocysteine-treated primary murine adipocytes and 3T3-L1 adipocytes (18). However, another previous study reported an opposite effect, in which activation of AMPK by BBR treatment promotes basal lipolysis in differentiated 3T3-L1 adipocytes (15). Additionally, Kim et al (19) demonstrated that adipose-tissue specific knockout of AMPK $\alpha 1 / \alpha 2$ in mice results in a decrease in basal lipolysis and enhances protein kinase A (PKA)-stimulated lipolysis in adipose tissue, suggesting that AMPK activation increases basal lipolysis and inhibits PKA-stimulated lipolysis. Thus, in BBR-treated adipocytes, whether AMPK is activated requires further investigation, as well as the regulatory role of AMPK activation in adipocyte lipolysis and the underlying molecular mechanism.

Pigs have abundant body fat and have many similar anatomical, genetical, metabolic and physiological characteristics to humans. Furthermore, pigs are more closely evolutionarily related to humans compared with rats and mice, which are two commonly used animal models. Thus, the pig is considered as an ideal medical model for researching human obesity and related metabolic diseases (20). In addition, pigs are an important source of meat products for humans worldwide and reduction of porcine fat deposition helps improve pork quality and production efficiency. Therefore, the aims of the present study were to investigate the effect of BBR on lipolysis in porcine adipocytes and identify the potential molecular mechanisms.

\section{Materials and methods}

Reagents.DMEM/NutrientMixtureF12(DMEM/F12) and penicillin-streptomycin were obtained from Gibco (Thermo Fisher Scientific, Inc.). HEPES, BSA, FBS, glycerol assay kit (cat. no. MAK117), cAMP Enzyme Immunoassay kit (cat. no. CA 200), recombinant human tumor necrosis factor $\alpha(\mathrm{TNF} \alpha)$, isoprenaline (ISO), DMSO, H89, compound C and polybrene were obtained from Sigma-Aldrich (Merck KGaA). Lentiviral vector pRNAT-U6.2/Lenti was obtained from GenScript Biotech Corporation. ViraPower Packaging mix, 293FT cell line, Lipofectamine 2000, type I collagenase and TRIzol ${ }^{\circledR}$ reagent were purchased from Invitrogen (Thermo Fisher Scientific, Inc.). PrimeScript reverse transcription (RT) Master mix was obtained from Takara Biotechnology Co., Ltd. SYBR Premix Ex Taq II kit was obtained from Takara Bio, Inc.

Phosphatase inhibitor cocktail (cat. no. 5870), protease inhibitor cocktail (cat. no. 5871), rabbit polyclonal antibodies to AMPKa1 (cat. no. 2795), phosphorylated (p)-AMPK $\alpha$ (cat. no. 2531) and rabbit anti- $\beta$-actin monoclonal antibody (cat. no. 4970) were obtained from Cell Signaling Technology, Inc. Rabbit anti-HSL polyclonal antibody (cat. no. abs131895) was obtained from Absin Biotechnology, Co. Ltd. Rabbit polyclonal antibody to p-HSL (cat. no. bs-3222R) was obtained from Bioss Biotechnology Co., Ltd. Rabbit polyclonal antibodies to Perilipin A (cat. no. ab126639), ATGL (cat. no. ab99532), p-ATGL (cat. no. ab135093), p-IRS1 (cat. no. ab1194), carnitine palmitoyl-transferase-1 (CPT-1; cat. no. ab83862), uncoupling protein 2 (UCP2; cat. no. ab97931) and goat anti-peroxisome proliferator-activated receptor $\gamma$ coactivator- $1 \alpha$ (PGC-1 $\alpha$ ) polyclonal antibody (cat. no. ab106814) were obtained from Abcam. Rabbit anti-IRS-1 monoclonal antibody (cat. no. MA5-15068) was obtained from Invitrogen (Thermo Fisher Scientific, Inc.).

Monoclonal secondary antibodies of mouse anti-rabbit IgG-horseradish peroxidase (HRP)-conjugate (cat. no. sc-2357) and mouse anti-goat IgG-HRP (cat. no. sc-2354) were obtained from Santa Cruz Biotechnology, Inc. Enhanced chemiluminescence (ECL) reagent and bicinchoninic acid (BCA) protein assay kit were purchased from Pierce (Thermo Fisher Scientific, Inc.). Cell Counting Kit-8 (CCK-8) was obtained from Vazyme Biotech Co., Ltd. TG assay kit (cat. no. E1013) was obtained from Applygen Technologies, Inc. The specific primer sequences for reverse transcription-quantitative PCR were synthesized in Aoke Biotechnology Corporation. BBR (with purity of $>98 \%$ ) was obtained from the National Institute for the Control of Pharmaceutical and Biological Products.

Experimental animals. Healthy male or female crossbred piglets (Duroc x Landrace x Large-White; age, 3 days) were provided by the Jinfeng Livestock Farm of Linfen. The animals were housed in a temperature-controlled room $\left(23 \pm 2^{\circ} \mathrm{C}\right)$ with 40-50\% air relative humidity and a 12-h light/12-h dark cycle under specific-pathogen free conditions, and allowed access to food and water ad libitum. A total of 76 piglets were used in the present study (38 male and 38 female; weight, $1.5-2.0 \mathrm{~kg}$ ). In each experiment, two piglets ( 1 female and 1 male) were euthanized by $\mathrm{CO}_{2}$ asphyxiation to reduce suffering. All experimental procedures involving animals were strictly carried out according to The Guide for The Care and Use of Laboratory Animals and were approved by The Institutional Ethics Committee of Shanxi Normal University.

Porcine preadipocytes primary culture, differentiation and drug treatment. The WAT of newborn piglets mainly resides in subcutaneous fat depots (21). According to our previous established method (22), adipose tissue was isolated from neck and back of the piglets, and was rinsed with DMEM/F12 basal culture medium (pH 7.4; 1:1 mixture of DMEM and F12; $100 \mathrm{mmol} / 1 \mathrm{HEPES} ; 50 \mathrm{U} / \mathrm{ml}$ penicillin-streptomycin) under sterile conditions. Tissue was then minced and digested with $1 \mathrm{mg} / \mathrm{ml}$ type I collagenase in DMEM/F12 basal culture 
medium containing $20 \mathrm{mg} / \mathrm{ml} \mathrm{BSA}$, in a $37^{\circ} \mathrm{C}$ shaking water bath for $1 \mathrm{~h}$. This was then filtered through a $200-\mu \mathrm{m}$ nylon mesh and centrifuged at $395 \mathrm{x}$ g for $8 \mathrm{~min}$ at room temperature. Collected pellets from the stromal-vascular fraction were used as preadipocytes and were resuspended in DMEM/F12 complete culture medium consisting of DMEM/F12 basal culture medium and $10 \%$ FBS.

The preadipocytes were seeded in $35 \mathrm{~mm}$ diameter culture dishes at a density of $5 \times 10^{4}$ cells $/ \mathrm{cm}^{2}$ and maintained at $37^{\circ} \mathrm{C}$ in a $5 \% \mathrm{CO}_{2}$ humidified atmosphere. DMEM/F12 complete medium can be used for proliferation and differentiation of primary porcine preadipocytes, without having to add a specific differentiation cocktail (23). Medium was changed every 2 days. The day of seeding was set as day 0 . Morphology of lipids accumulation in adipocytes was observed with an Olympus IX53 inverted light microscope (magnification, x200; Olympus Corporation). During differentiation of preadipocytes, the small lipid droplets in cells converged into larger lipid droplets, indicating that the cultured adipocytes were unilocular white adipocytes, rather than multilocular brown adipocytes.

In contrast to fresh isolated mature adipocytes, preadipocytes have the ability to divide and proliferate. After proliferation and differentiation, additional adipocytes can be obtained for subsequent experimental studies. Therefore, in the present study, preadipocytes were isolated and cultured instead of using mature adipocytes.

To examine the effect of BBR on lipolysis, differentiated porcine adipocytes were incubated with various concentrations (0-40 $\mu \mathrm{M})$ of BBR (National Institute for the Control of Pharmaceutical and Biological Products) at $37^{\circ} \mathrm{C}$ for $24-72 \mathrm{~h}$. To assess whether BBR activated the AMPK signaling pathway, differentiated porcine adipocytes on day 5 were pre-treated with or without various concentrations of AMPK inhibitor compound $\mathrm{C}(10$ or $20 \mu \mathrm{M})$ at $37^{\circ} \mathrm{C}$ for $24 \mathrm{~h}$, then incubated with or without $30 \mu \mathrm{M}$ BBR in the continued absence or presence of the inhibitor at $37^{\circ} \mathrm{C}$ for a further $48 \mathrm{~h}$. Furthermore, to determine the effect of BBR-induced lipolysis on insulin signaling, a positive control trial was performed, in which differentiated porcine adipocytes on day 6 were incubated with $10 \mathrm{ng} / \mathrm{ml}$ TNFa (Sigma-Aldrich; Merck KGaA) at $37^{\circ} \mathrm{C}$ for $30 \mathrm{~min}$. BBR was dissolved in DMSO and the final concentration of DMSO in culture medium was $<0.1 \%(\mathrm{v} / \mathrm{v})$. The control group was treated with $2 \mu 1$ DMSO.

Lipolysis assay. Differentiated porcine adipocytes were treated with (+) or without (-) BBR $(10-40 \mu \mathrm{M}), \mathrm{H} 89(20 \mu \mathrm{M})$, ISO $(10 \mu \mathrm{M})$ or compound $\mathrm{C}(10-20 \mu \mathrm{M})$ at $37^{\circ} \mathrm{C}$ for $24-72 \mathrm{~h}$, 26-72 h, $2 \mathrm{~h}$ and $72 \mathrm{~h}$, respectively. Then, the glycerol content of the incubation medium was used as an index for lipolysis and was measured by a colorimetric method using glycerol assay kits according to the manufacturer's protocol. Glycerol concentration is presented as glycerol $(\mu \mathrm{mol} / \mathrm{ml})$.

Measurement of TG levels. Cells in 35-mm diameter culture dishes $\left(1 \times 10^{6}\right.$ cells/dish) were washed twice with ice-cold PBS and lysed using the lysis buffer provided in the TG assay kit, at room temperature for $10 \mathrm{~min}$. Lysates were divided into two parts and the concentrations of TG and total protein in each plate were measured with TG and BCA assay kits according to the manufacturer's protocols, respectively. TG content was expressed as mmol of TG/g of protein. Each group of cells was analyzed in triplicate and the experiments were repeated three times.

Cell viability assay. Cell viability was determined using CCK-8 assay according to the manufacturer's protocol. Porcine preadipocytes were seeded in 96-well culture plates at a density of $1.0 \times 10^{4}$ cells/well in $100 \mu 1$ volume. Cells were cultured in DMEM/F12 complete culture medium supplemented with $10 \% \mathrm{FBS}$ and $50 \mathrm{U} / \mathrm{ml}$ penicillin-streptomycin for $72 \mathrm{~h}$, and then treated with different concentrations of $\operatorname{BBR}(0,10,20$, 30 and $40 \mu \mathrm{M}$ ) for $48 \mathrm{~h}$. Then, $10 \mu \mathrm{l} \mathrm{CCK}-8$ solution was added into each well and incubated for a further $4 \mathrm{~h}$ at $37^{\circ} \mathrm{C}$. Absorbance was quantified at $450 \mathrm{~nm}$ using a Benchmark Plus microplate reader (Bio-Rad Laboratories, Inc.), and the relative viability of cells was presented as a percentage of the control.

Intracellular cAMP concentration assay. Differentiated porcine adipocytes on day 6 were incubated at $37^{\circ} \mathrm{C}$ with BBR $(10$ and $30 \mu \mathrm{M})$ for $48 \mathrm{~h}$ or ISO $(10 \mu \mathrm{M})$ for $2 \mathrm{~h}$. Then, intracellular cAMP content was measured using an ELISA kit according to the manufacturer's protocol. Data are presented as $\mathrm{cAMP}(\mathrm{pmol} / \mathrm{l})$.

Reverse transcription-quantitative $(R T-q) P C R$. Total RNA was extracted with TRIzol ${ }^{\circledR}$ reagent according to the manufacturer's protocol. Total RNA integrity was detected using a $2 \%$ agarose gel and the purity and concentration of the RNA preparation was assessed using a UV spectrophotometer. Possible genomic DNA contamination was eliminated by incubating total RNA with $3 \mathrm{U} / 10 \mu \mathrm{l}$ deoxyribonuclease I for $30 \mathrm{~min}$ at $37^{\circ} \mathrm{C}$. Then, $2 \mu \mathrm{g}$ total RNA was RT to synthesize first-strand cDNA using the PrimeScript RT-reagent kit using the following thermocycling conditions: $37^{\circ} \mathrm{C}$ for $15 \mathrm{~min}, 85^{\circ} \mathrm{C}$ for $5 \mathrm{sec}$ and $4^{\circ} \mathrm{C}$ for $5 \mathrm{~min}$.

qPCR reactions were performed in triplicate on a Bio-Rad iQ5 system (Bio-Rad Laboratories, Inc.) using a SYBR Premix Ex Taq II system in a final volume of $25 \mu \mathrm{l}$ (containing $12.5 \mu \mathrm{l}$ SYBR Premix Ex Taq II; $1 \mu 1$ sense primer; $1 \mu \mathrm{l}$ anti-sense primer; $1 \mu \mathrm{l}$ template cDNA; $9.5 \mu \mathrm{l}$ ddH2O). The conditions of qPCR were as follows: Initial denaturation at $95^{\circ} \mathrm{C}$ for $5 \mathrm{~min}$, followed by 40 cycles of melting at $95^{\circ} \mathrm{C}$ for $15 \mathrm{sec}$ and annealing/extension at $60^{\circ} \mathrm{C}$ for $35 \mathrm{sec}$. A melt curve was established at $60-95^{\circ} \mathrm{C}$ at the end of the amplification in order to determine specificity of the primers. The primer sequences used for qPCR were designed by Premier 5.0 software (Premier Biosoft International) and are listed in Table I. Amplification efficiency of the primers was between 90 and 100\%. Furthermore, 18S rRNA was amplified as an internal control. The $2^{-\Delta \Delta \mathrm{Cq}}$ method was used to analyze the relative mRNA expression of each gene of interest (24).

Western blotting. The cellular total protein was extracted with lysis buffer ( $\mathrm{pH} \mathrm{7.5)} \mathrm{containing} 50 \mathrm{mmol} / 1$ Tris- $\mathrm{HCl}$, $0.5 \%$ Triton X-100, $2 \mathrm{mmol} / 1$ EDTA, $150 \mathrm{mmol} / 1 \mathrm{NaCl}$, $1 \mathrm{mmol} / 1 \mathrm{PMSF}, 1 \%$ protease inhibitor cocktail and $1 \%$ phosphatase inhibitor cocktail. Protein quality was determined on $12 \%$ SDS-PAGE gel with $0.25 \%$ (w/v) coomassie brilliant blue R250 staining at room temperature for $2 \mathrm{~h}$ followed by 
Table I. Specific primers used for quantitative PCR.

\begin{tabular}{|c|c|c|c|}
\hline Gene & GenBank accession no. & Primer (5'-3') & Product length, bp \\
\hline Perilipin A & NM_001038638 & 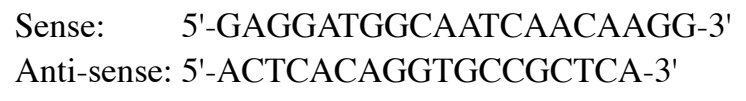 & 110 \\
\hline ATGL & EU373817 & $\begin{array}{ll}\text { Sense: } & \text { 5'-ACCCTGTCCAACCTGCTGC-3' } \\
\text { Anti-sense: 5'-GCCTGTCTGCTCCTTTATCCA-3' }\end{array}$ & 153 \\
\hline HSL & AJ000482 & $\begin{array}{lr}\text { Sense: } & \text { 5'-TTTGAAATGCCACTGACTGC-3' } \\
\text { Anti-sense: } & \text { 5'-TAGGAGATGAGCCTGACGAG-3' }\end{array}$ & 101 \\
\hline PGC-1 $1 \alpha$ & NM_213963 & $\begin{array}{l}\text { Sense: } \quad \text { 5'-CAGCGAAGATGAAAGTGA-3' } \\
\text { Anti-sense: 5'-AATAAGGATTTGGGTGGT-3' }\end{array}$ & 135 \\
\hline TFAM & NM_001130211 & $\begin{array}{l}\text { Sense: } \quad \text { 5'-TCCTTCGTCGTAGTCCCG-3' } \\
\text { Anti-sense: 5'-TGAACTCGCAAGCAACTC-3' }\end{array}$ & 159 \\
\hline CPT-1 & NM_001129805 & $\begin{array}{l}\text { Sense: } \quad \text { 5'-CATTTGTCCCATCTTTCG-3' } \\
\text { Anti-sense: 5'-CTTGTCCACTTGCTACGC-3' }\end{array}$ & 146 \\
\hline UCP-2 & NM_214289 & $\begin{array}{lr}\text { Sense: } & \text { 5'-CCCAATGTCGCTCGTAATG-3' } \\
\text { Anti-sense: 5'-GAAGGCGGACGTGAAGTG-3' }\end{array}$ & 126 \\
\hline $18 \mathrm{~S}$ rRNA & AY265350 & $\begin{array}{l}\text { Sense: } \quad \text { 5'-CCCACGGAATCGAGAAAGAG-3' } \\
\text { Anti-sense: } \\
\text { 5'-TTGACGGAAGGGCACCA-3' }\end{array}$ & 122 \\
\hline
\end{tabular}

ATGL, adipose triglyceride lipase; HSL, hormone sensitive lipase; CPT-1, carnitine palmitoyl-transferase-1; PGC-1 $\alpha$, peroxisome proliferator-activated receptor $\gamma$ coactivator-1 $\alpha$; TFAM, mitochondrial transcription factor A; UCP2, uncoupling protein 2.

decolorization for $4 \mathrm{~h}$, and the protein concentration was measured using a BCA protein assay kit.

Total proteins $(50 \mu \mathrm{g})$ were electrophoresed using $12 \%$ SDS-PAGE under reducing conditions, followed by electro-transfer onto PVDF membranes. After blocking with 5\% BSA in TBST ( $\mathrm{pH} 7.5 ; 100 \mathrm{mmol} / 1$ Tris; $154 \mathrm{mmol} / \mathrm{l}$ $\mathrm{NaCl} ; 0.1 \% \mathrm{v} / \mathrm{v}$ Tween-20) for $60 \mathrm{~min}$ at room temperature, the membranes were reacted with primary antibodies to Perilipin A (1:800), ATGL (1:1,000), p-ATGL (1:1,000), HSL (1:400),

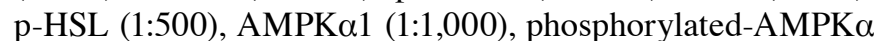
(1:1,000), PGC-1 $\alpha$ (1:400), CPT-1 (1:1,000), UCP2 (1:800), IRS-1 (1:1,000), p-IRS-1 (1:200) and $\beta$-actin (internal control; $1: 1,000)$ overnight at $4^{\circ} \mathrm{C}$. Subsequently, the membranes were washed three times with TBST $(0.1 \%$ Tween-20), followed by incubation with HRP-conjugated secondary antibodies of mouse anti-rabbit $\operatorname{IgG}(1: 1,000)$ or mouse anti-goat $\mathrm{IgG}$ $(1: 1,000)$ for $60 \mathrm{~min}$ at room temperature. Membranes were then visualized using an ECL reagent. Densitometric analysis of protein bands was performed using ImageJ software (version 1.8.0.112; National Institutes of Health).

Lentivirus-mediated RNA interference (RNAi). AMPK $\alpha 1$ small hairpin RNA (shRNA)design was based on 122-140 of porcine AMPK $\alpha 1$ mRNA (GenBank accession no. AB530142; National Center for Biotechnology Information). A scrambled shRNA (based on the sequence 5'-GCATCAT CACTCAATCCAA-3') was generated as a negative control to investigate the non-specific effect of AMPK $\alpha 1$ shRNA on adipocytes lipolysis. To construct recombinant expression plasmids, AMPK $\alpha 1$ shRNA and scrambled shRNA oligonucleotides were cloned into pRNAT-U6.2/Lenti vectors between BamHI and XhoI sites.
shRNA-expressing plasmids $(3 \mu \mathrm{g})$ and ViraPower Packaging mix $(9 \mu \mathrm{g})$ containing $\mathrm{pLP} 1, \mathrm{pLP} 2$ and $\mathrm{pLP} / \mathrm{VSVG}$ plasmids were co-transfected into $293 \mathrm{FT}$ cells $\left(6 \times 10^{6}\right)$ in a $10 \mathrm{~cm}$ culture dish using Lipofectamine 2000, according to the manufacturer's protocol. The $10 \mathrm{ml}$ supernatants containing lentivirus particles in each dish were collected $48-72 \mathrm{~h}$ post-transfection and passed through sterile $0.45 \mu \mathrm{m}$ PVDF filters to remove cellular debris. Then, titers of the recombinant lentivirus supernatants were determined and the virus stocks were stored at $-80^{\circ} \mathrm{C}$.

In $35 \mathrm{~mm}$ culture dish, differentiated porcine adipocytes on day 5 were infected with $200 \mu$ lentivirus stock $\left(5 \times 10^{6} \mathrm{TU} / \mathrm{ml}\right)$ containing AMPK $\alpha 1$ shRNA or scrambled shRNA in the presence of $6 \mu \mathrm{g} / \mathrm{ml}$ polybrene. Medium was replaced with fresh DMEM/F12 complete culture medium after $24 \mathrm{~h}$. Adipocytes were cultured for a further $48 \mathrm{~h}$, then RT-qPCR and western blotting were used to assess RNAi efficiency. The recombinant lentivirus that was identified to have the highest inhibitory effect on AMPK $\alpha 1$ gene expression was selected for AMPK $\alpha 1$ knockdown in subsequent experimentations.

Statistical analysis. All experiments were conducted three times. Data are presented as the mean \pm SEM and were analyzed using SPSS 17.0 software (IBM Corp.). Individual comparisons were evaluated using an unpaired Student's t-test. Multiple comparisons were determined by one-way or two-way ANOVA followed by a Tukey's post hoc test. $\mathrm{P}<0.05$ was considered to indicate a statistically significant difference.

\section{Results}

BBR induces lipolysis in differentiated porcine adipocytes. To investigate the mechanism by which BBR regulates lipolysis in 

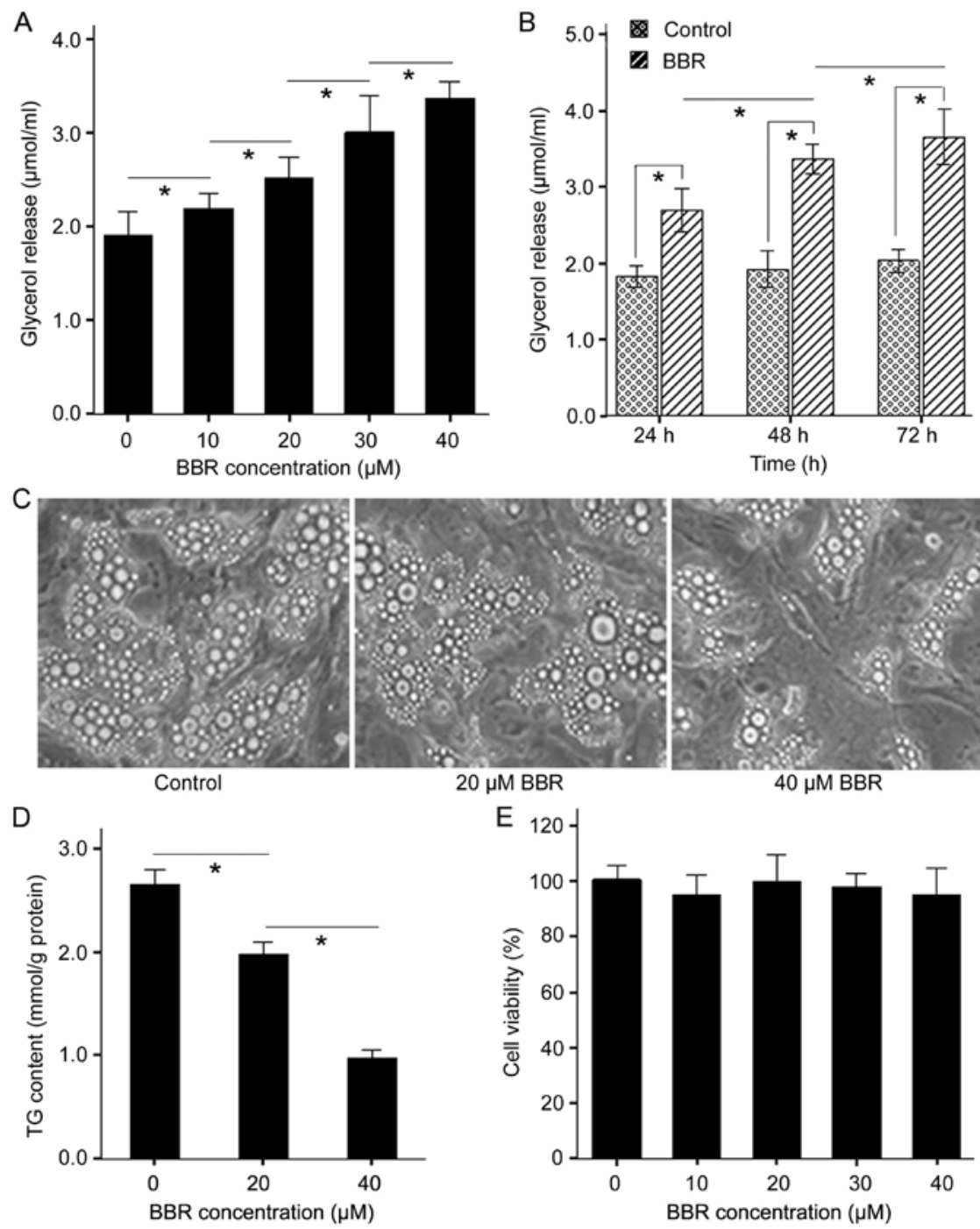

Figure 1. Dose- and time-dependent effect of BBR on lipolysis in porcine adipocytes. Differentiated porcine adipocytes on day 6 were incubated with various concentrations of BBR for $48 \mathrm{~h}$, or $30 \mu \mathrm{M}$ BBR at different time points. Glycerol release was determined as a measure of lipolysis. (A) Dose-dependent effect of BBR on lipolysis in porcine adipocytes. (B) Time-dependent effect of BBR on lipolysis in porcine adipocytes. (C) Morphology of lipid accumulation in adipocytes after treatment with 20 and $40 \mu \mathrm{M}$ BBR for $48 \mathrm{~h}$. Magnification, x200. (D) TG content analysis of the adipocytes treated with different concentrations of BBR for $48 \mathrm{~h}$. Intracellular TG contents were normalized by total protein and both originated from one sample. (E) Cell viability was detected using a Cell Counting Kit- 8 assay after treatment with 0-40 $\mu \mathrm{M}$ BBR for $48 \mathrm{~h}$. Data are presented as the mean \pm SEM of triplicate measurements. ${ }^{*}<0.05$. BBR, berberine; TG, triglyceride.

porcine adipocytes, the present study examined the effect of BBR on lipolysis. It was found that treatment of adipocytes with BBR (10-40 $\mu \mathrm{M})$ for $48 \mathrm{~h}$ caused a dose-dependent increase in glycerol release (Fig. 1A). Moreover, the maximal glycerol release was seen in the $40 \mu \mathrm{M}$ treated group and was $\sim 47.2 \%$ higher compared with the control. Furthermore, it was demonstrated that BBR treatment significantly reduced lipid content in fat droplets of porcine adipocytes in a dose-dependent manner (Fig. 1C and D). However, BBR (10-40 $\mu \mathrm{M})$ did not alter cell viability after $48 \mathrm{~h}$ treatment (Fig. 1E). Furthermore, adipocytes released more glycerol at $72 \mathrm{~h}$ compared with $48 \mathrm{~h}$ in response to $30 \mu \mathrm{M}$ BBR and the minimal glycerol release was seen in $24 \mathrm{~h}$ after treatment (Fig. 1B). Therefore, the present results suggested that BBR induced lipolysis in porcine adipocytes in a dose- and time-dependent manner, which was not related to cytotoxicity.

cAMP/PKA pathway is not involved in BBR-induced lipolysis. In adipocytes, cAMP-dependent PKA activation is an important event in lipolysis, which is stimulated by catecholamines (25). To assess whether the cAMP/PKA pathway mediated BBR-induced lipolysis, the present study directly measured intracellular cAMP content after treatment with BBR or ISO, a $\beta$-adrenergic agonist and an activator of adenylyl cyclase. It was found that treatment of adipocytes with $10 \mu \mathrm{M}$ ISO caused a significant elevation in cAMP (Fig. 2A). However, both 10 and $30 \mu \mathrm{M}$ BBR treatments did not have effect on cAMP content in cells compared with the control. To further examine the role of the cAMP/PKA pathway in BBR-induced lipolysis, a specific PKA inhibitor H89 was used to block activation of PKA. The present results identified that stimulation of adipocytes with $10 \mu \mathrm{M}$ ISO resulted in a significant increase in glycerol release and this effect was abrogated by $20 \mu \mathrm{M}$ H89 (Fig. 2B). In contrast, H89 pretreatment failed to suppress $30 \mu \mathrm{M}$ BBR-induced lipolysis. Collectively, the present results indicated that BBR-induced lipolysis does not involve the activation of the $\mathrm{CAMP} / \mathrm{PKA}$ pathway. 

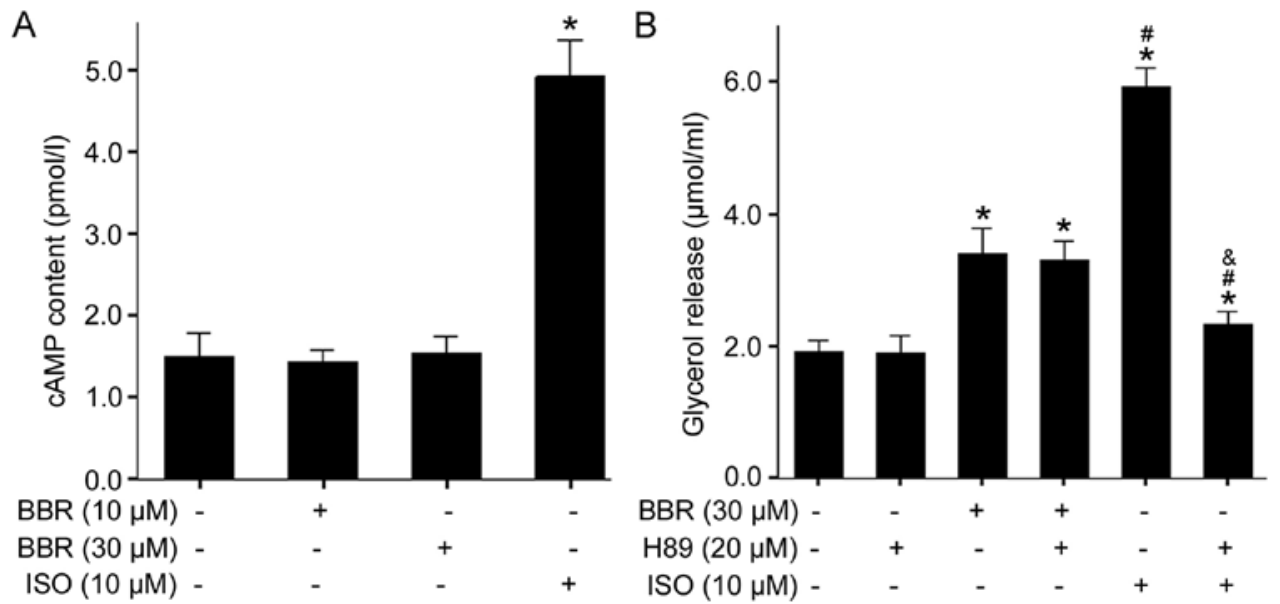

Figure 2. BBR does not affect intracellular cAMP level and PKA activation. (A) BBR did not increase intracellular cAMP level. (B) PKA inhibitor H89 did not suppress BBR-induced lipolysis. Differentiated porcine adipocytes on day 6 were pretreated + or $-20 \mu \mathrm{M}$ PKA inhibitor H89 for $24 \mathrm{~h}$ and then incubated + or $-30 \mu \mathrm{M}$ BBR or $10 \mu \mathrm{M}$ ISO. Glycerol concentration in the culture medium was then measured. Data are presented as the mean \pm SEM of triplicate measurements. ${ }^{~} \mathrm{P}<0.05$ vs. control. ${ }^{\text {}} \mathrm{P}<0.05$ vs. BBR-treated group. ${ }^{~} \mathrm{P}<0.05$ vs. ISO-treated group. + , with; -, without; PKA, protein kinase A; BBR, berberine; ISO, isoprenaline.

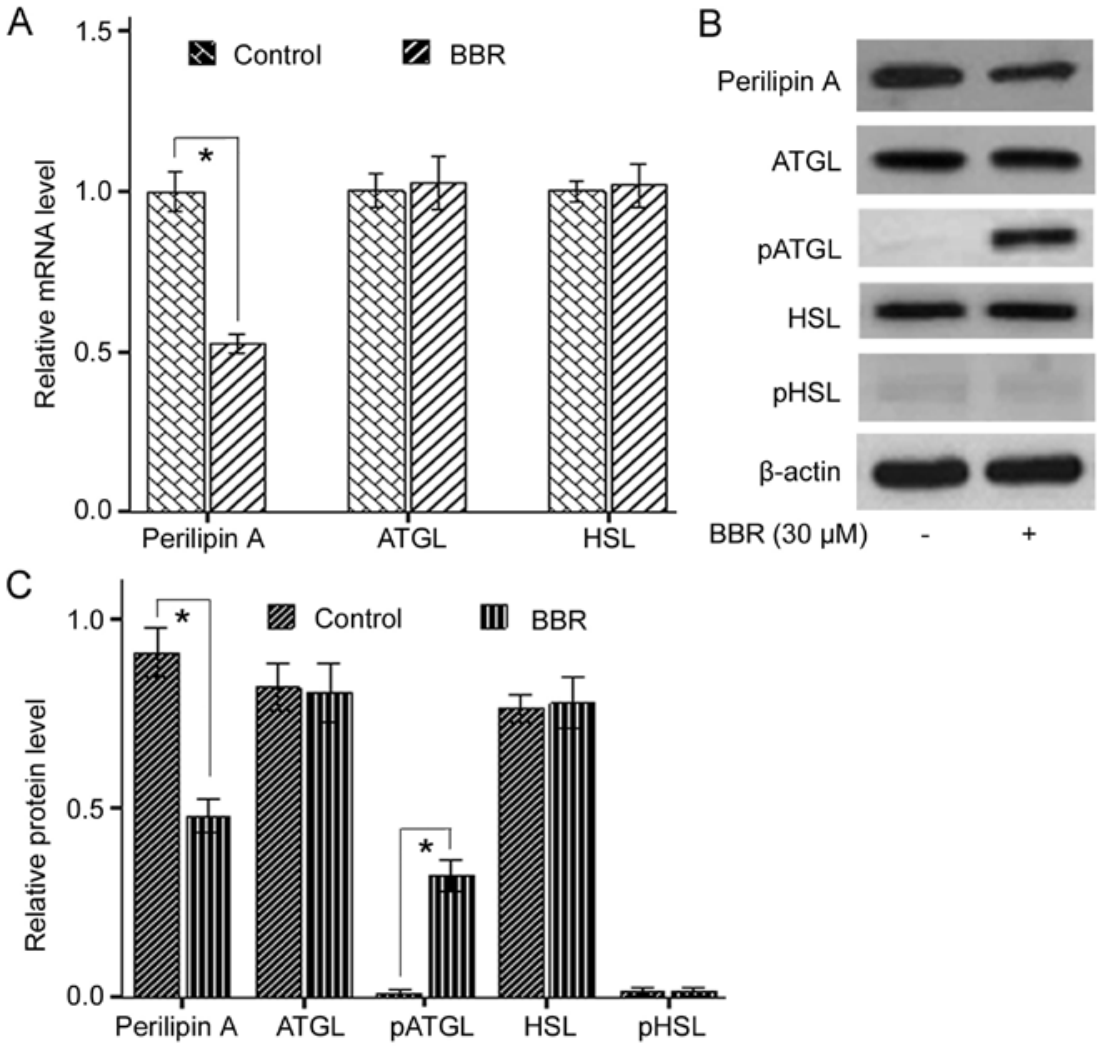

Figure 3. Effect of BBR on expression levels of lipolysis-related genes and phosphorylation of lipases. Differentiated porcine adipocytes on day 6 were incubated with $30 \mu \mathrm{M}$ BBR for $48 \mathrm{~h}$. (A) Effect of BBR on mRNA expression levels of Perilipin A, ATGL and HSL. (B) Effect of BBR on protein expression levels of Perilipin A, ATGL, HSL, pATGL and pHSL. Representative images were obtained from four or five independent experiments. (C) Relative protein expression levels of Perilipin A, ATGL, HSL, pATGL and pHSL normalized to $\beta$-actin. Data are presented as the mean \pm SEM of triplicate measurements. ${ }^{\text {"P}} \mathrm{P}$ 0.05. p-, phosphorylated; ATGL, adipose triglyceride lipase; HSL, hormone sensitive lipase; BBR, berberine.

Effect of BBR on expression of related genes to lipolysis and activation of lipases. Hydrolysis of TG in adipocytes is caused by catalysis of lipases and regulation of several protein factors. To investigate the effect of BBR on the expression levels of lipolysis related genes, the present study analyzed mRNA and protein expression levels of ATGL, HSL and Perilipin A. It was demonstrated that $30 \mu \mathrm{M}$ BBR treatment significantly decreased Perilipin A mRNA and protein expression levels compared with the control, whereas the mRNA and protein expression levels of ATGL and HSL were not affected (Fig. 3A-C). Subsequently, the effects of BBR on the activation of ATGL and HSL were examined. It was found that 
A

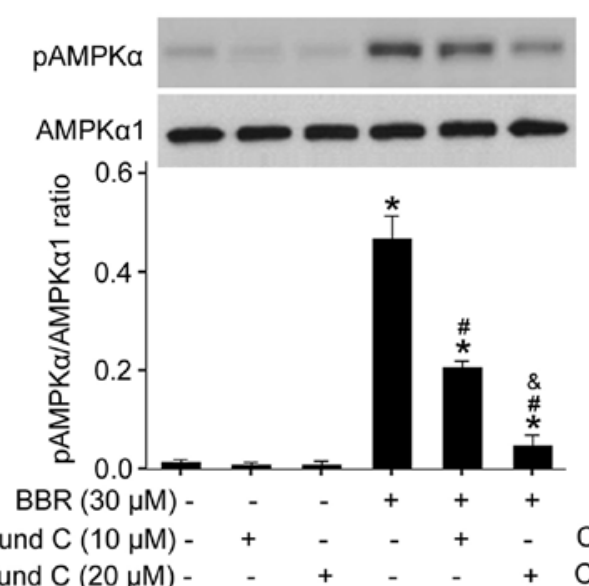

B

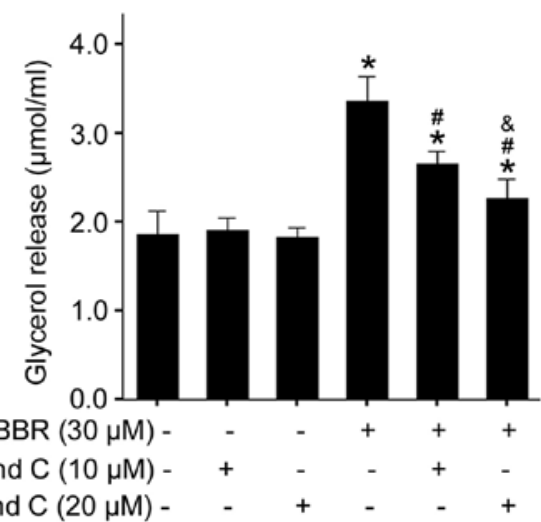

Compound C $(20 \mu \mathrm{M})$ -

Compound C $(10 \mu \mathrm{M})-$
$+\quad$ Compound $C(20 \mu \mathrm{M})-$

C
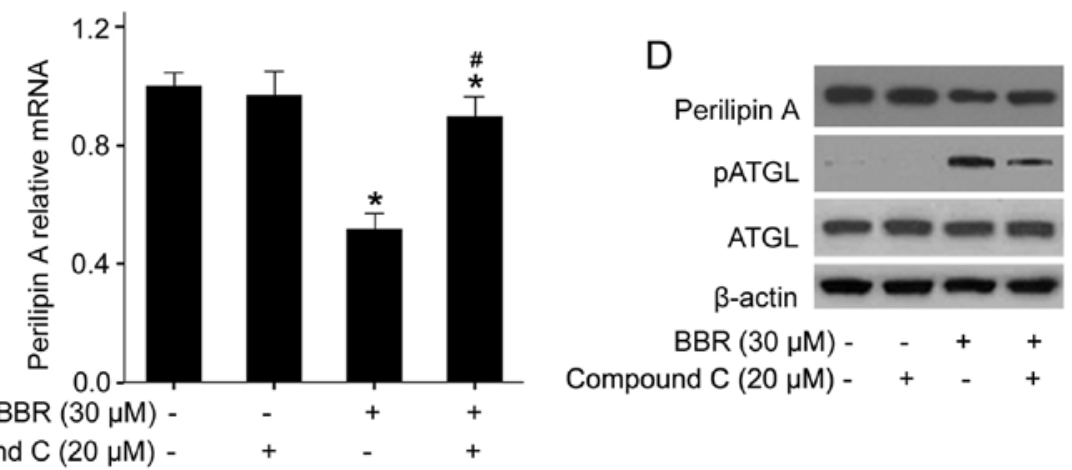

Compound C $(20 \mu \mathrm{M})$ -

E

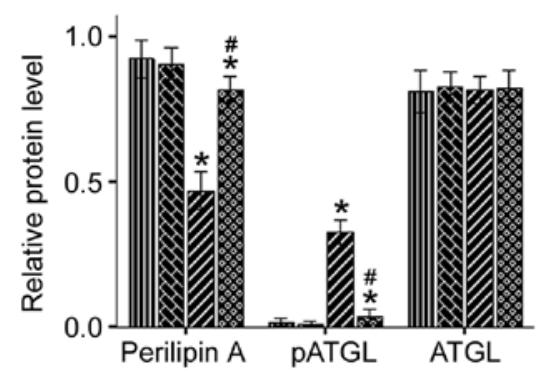

III Control

N Compound C

Q BBR

BBR+Compound C

Figure 4. Effect of the AMPK pathway on BBR-induced lipolysis. Differentiated porcine adipocytes on day 5 were pretreated + or - various concentrations of AMPK inhibitor compound $\mathrm{C}$ for $24 \mathrm{~h}$, then incubated + or $-30 \mu \mathrm{M}$ BBR. Glycerol concentration in the culture medium was measured. (A) BBR activated AMPK in porcine adipocytes. (B) AMPK inhibitor compound C attenuated BBR-induced lipolysis. (C) AMPK inhibitor compound C rescued BBR-suppressed mRNA expression of Perilipin A. (D) AMPK inhibitor compound C reversed the effects of BBR on Perilipin A protein expression and ATGL phosphorylation. Representative images were obtained from four or five independent experiments. (E) Relative protein expression levels of Perilipin A, pATGL and ATGL normalized to $\beta$-actin. Data are presented as the mean \pm SEM of triplicate measurements. ${ }^{*} \mathrm{P}<0.05$ vs. untreated control. ${ }^{~} \mathrm{P}<0.05$ vs. BBR-treated group. ${ }^{\&} \mathrm{P}<0.05$ vs. BBR $+10 \mu \mathrm{M}$ compound $\mathrm{C}$ group. AMPK $\alpha$, AMP-activated protein kinase $\alpha$; ATGL, adipose triglyceride lipase; p-, phosphorylated; +, with; -, without; BBR, berberine.

BBR treatment significantly increased phosphorylation of ATGL, but had no effect on phosphorylation of HSL at the PKA site (Fig. 3B and C). Thus, the present results indicated that BBR induced lipolysis in porcine adipocytes via a reduction of Perilipin A and elevation of ATGL phosphorylation.

AMPK pathway mediates BBR-induced lipolysis. AMPK is a master regulator of cellular energy homeostasis and plays a vital role in lipid metabolism $(17,26)$. To determine the relationship between the AMPK pathway and BBR-induced lipolysis, the effect of BBR on AMPK activation was examined. The present results identified that $30 \mu \mathrm{M}$ BBR treatment significantly enhanced AMPK $\alpha$ phosphorylation (Fig. 4A). Moreover, pretreatment of adipocytes with 10 and $20 \mu \mathrm{M}$ compound $\mathrm{C}$, a specific inhibitor of AMPK, attenuated
BBR-stimulated phosphorylation of AMPK $\alpha$, thus indicating that BBR activates AMPK in porcine adipocytes. Furthermore, it was demonstrated that $20 \mu \mathrm{M}$ compound $\mathrm{C}$ could efficiently suppress the activation of AMPK.

To further investigate the possible role of the AMPK pathway in BBR-induced lipolysis, the specific AMPK inhibitor compound $\mathrm{C}$ was used to block activation of the AMPK signaling pathway. It was found that pretreatment of porcine adipocytes with a low dose of compound C $(10 \mu \mathrm{M})$ only partly impaired BBR-induced lipolysis, whereas a high dose of compound $\mathrm{C}(20 \mu \mathrm{M})$ almost completely abolished BBR-induced lipolysis (Fig. 4B). Moreover, $20 \mu \mathrm{M}$ compound C significantly reversed BBR-suppressed mRNA and protein expression of Perilipin A, as well as BBR-enhanced phosphorylation of ATGL, however the protein expression level of ATGL 

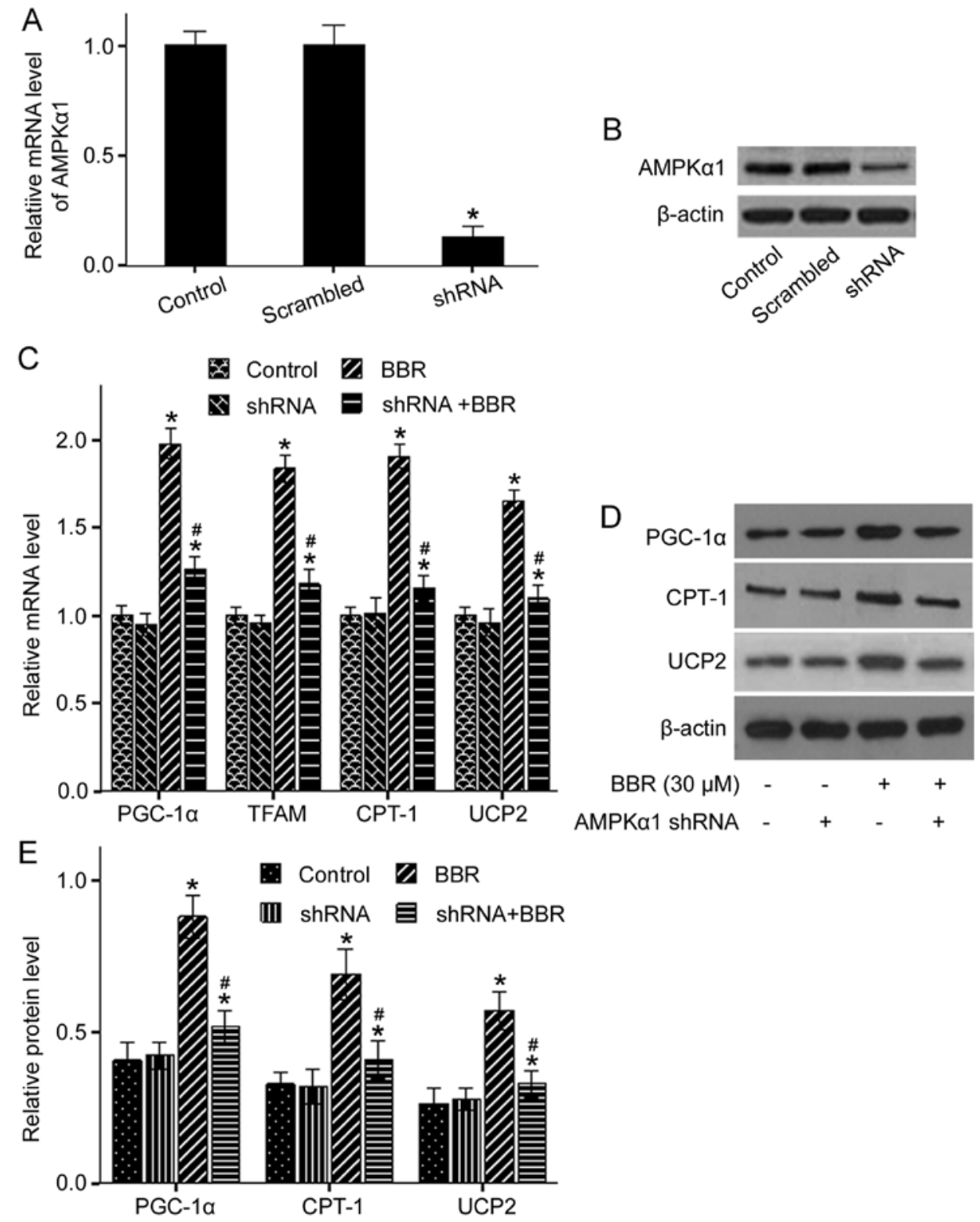

Figure 5. Effect of AMPK $\alpha 1$ knockdown on expression of related genes to free fatty acid oxidation in BBR-treated adipocytes. AMPK $\alpha 1$ gene was successfully knocked down by specific shRNA transfection. (A) Relative mRNA expression of AMPK $\alpha 1$ gene. (B) Western blot analysis of AMPKa1. Differentiated porcine adipocytes on day 5 were infected + or - AMPK $\alpha 1$ shRNA for $24 \mathrm{~h}$ and then incubated + or $-30 \mu \mathrm{M}$ BBR for a further $48 \mathrm{~h}$. (C) Relative mRNA expression levels of PGC-1 $\alpha$, TFAM, CPT-1 and UCP2. (D) Western blot analysis of PGC-1 $\alpha$, CPT-1 and UCP2. Representative images were obtained from four or five independent experiments. (E) Relative protein expression levels of PGC-1 $\alpha$, CPT-1 and UCP2 normalized to $\beta$-actin. Data are presented as the mean \pm SEM of triplicate measurements. ${ }^{~} \mathrm{P}<0.05$ vs. untreated control cells. ${ }^{\prime \prime} \mathrm{P}<0.05$ vs. BBR-treated group. shRNA, short hairpin RNA; AMPK $\alpha$, AMP-activated protein kinase $\alpha$; Scrambled group, scrambled shRNA; shRNA group, AMPK $\alpha 1$ shRNA; +, with; -, without; BBR, berberine; CPT-1, carnitine palmitoyl-transferase-1; PGC-1 $\alpha$, peroxisome proliferator-activated receptor $\gamma$ coactivator-1 $\alpha$; TFAM, mitochondrial transcription factor A; UCP2, uncoupling protein 2.

was unchanged (Fig. 4C-E). Therefore, the AMPK pathway may mediate BBR-induced lipolysis in porcine adipocyte via downregulation of Perilipin A and activation of ATGL.

BBR promotes expression of related genes to FFA oxidation via the AMPK pathway. FA oxidation can decrease the end products of lipolysis, which helps to maintain and promote adipocytes lipolysis (27). In order to assess the effect of BBR on FA oxidation in porcine adipocytes, the present study used sh-AMPK $\alpha 1$ to block the AMPK pathway and then evaluated expression levels of the genes related to mitochondrial FA oxidation in response to BBR treatment. It was identified that adipocytes transfected with AMPK $\alpha 1$ shRNA for $72 \mathrm{~h}$ had a significant decrease in the expression of AMPK $\alpha 1$ compared with the control (Fig. 5A and B). The AMPK $\alpha 1$ mRNA expression level was $\sim 86.6 \%$ lower compared with the control. Furthermore, adipocytes transfected with AMPK $\alpha 1$ shRNA had a significant reduction in protein expression level of AMPK $\alpha 1$, which paralleled decreased mRNA expression. In contrast, transfection with scrambled shRNA had no effect on the mRNA and protein expression levels of AMPK $\alpha 1$. Thus, the present results suggested that AMPK $\alpha 1$ was successfully knocked down by the transfection of AMPK $\alpha 1$ shRNA in porcine adipocytes. Therefore, the recombinant lentivirus containing AMPK $\alpha 1$ shRNA was used to knockdown AMPK $\alpha 1$ in the subsequent experiments. 
A

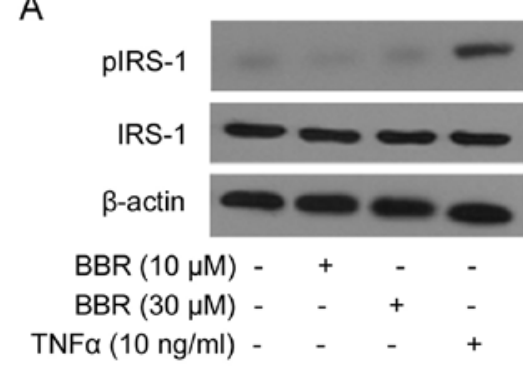

B

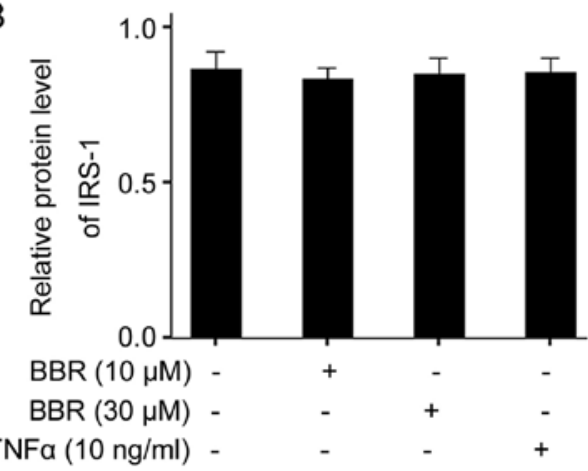

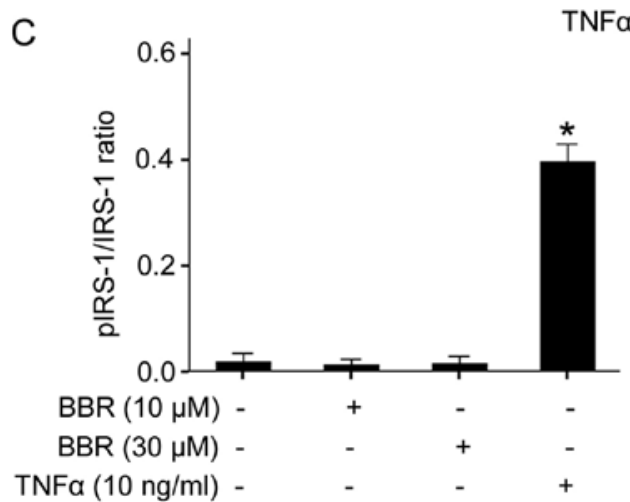

Figure 6. BBR does not affect expression and serine phosphorylation of IRS-1 protein. (A) Representative protein expression levels of IRS-1, pIRS-1 and $\beta$-actin. (B) Relative expression of IRS-1 protein. (C) Serine phosphorylation level of IRS-1 protein. Representative images were obtained from four or five independent experiments. Data are presented as the mean \pm SEM of triplicate measurements. ${ }^{*} \mathrm{P}<0.05$ vs. control. IRS, IRS-1, insulin receptor substrate-1; p-, phosphorylated; +, with; -, without; BBR, berberine; TNF $\alpha$, tumor necrosis factor $\alpha$.

The present study demonstrated that $30 \mu \mathrm{M}$ BBR alone significantly increased the mRNA expression levels of PGC-1 $\alpha$, TFAM, CPT-1 and UCP2 compared with the control, which were significantly abrogated by AMPK $\alpha 1$ knockdown (Fig. 5C). Moreover, alterations in protein expression levels of PGC-1 $\alpha$, CPT-1 and UCP2 were similar to that of the mRNA expression levels (Fig. 5C-E). Collectively, the present results suggested that BBR may promote FFA oxidation in porcine adipocytes via the upregulation of PGC- $1 \alpha$, TFAM, CPT-1 and $\mathrm{UCP} 2$, which may be mediated by the AMPK pathway.

BBR-induced lipolysis does not block insulin signaling at the level of IRS-1. FFA from increased lipolysis may block insulin signaling via serine phosphorylation of IRS proteins, leading to insulin resistance (28). To determine the effect of BBR-induced lipolysis on insulin signaling, the present study examined the protein expression level and serine phosphorylation of IRS-1 in BBR-treated adipocytes. It was found that both 10 and $30 \mu \mathrm{M}$ BBR treatment did not affected the protein expression of IRS-1, and did not increase serine phosphorylation of IRS-1 compared with the control (Fig. 6A-C). In contrast, treatment of adipocytes with TNF $\alpha$, a known inducer of lipolysis, significantly increased IRS-1 serine phosphorylation, although it also did not alter the protein expression of IRS-1. Therefore, BBR-induced lipolysis may not block insulin signaling at the level of IRS-1 in porcine adipocytes.

\section{Discussion}

BBR, a traditional Chinese herb active ingredient, has been used to treat gastroenteritis and diarrhea (29). Previous studies have focused on its regulatory effect on obesity and insulin resistance (30-32). Lipolysis decreases TG content in adipocytes, which is important for combating obesity $(19,22)$. However, continuous lipolysis may increase plasma FFA level and induce systematic insulin resistance (8), which is one of the most important factors of the pathogenesis of obesity-associated metabolic disorders, involving hyperglycemia, hyperlipidemia, hypertension and type 2 diabetes (33). Moreover, enhancement of FA oxidation during adipocyte lipolysis can contribute to a decrease in FFA accumulation and thus helps to maintain lipolysis and improve insulin resistance (34).

The aims of the present study were to investigate the lipolytic role of BBR in primary porcine adipocytes and to identify the underlying signaling mechanisms. To the best of our knowledge, the present study was the first demonstration of this effect in porcine adipocytes. It was demonstrated that BBR induced lipolysis by activation of the AMPK pathway, suppression of Perilipin A, phosphorylation of ATGL and upregulation of genes related to FA oxidation. Furthermore, this lipolytic action did not impair insulin signaling at IRS-1 level, which may be attributed to enhanced FA oxidation in adipocytes. Therefore, the present results provided evidence that BBR may be used as a lipolytic inducer and could exert beneficial regulatory effects on obesity and insulin resistance.

Adipocytes lipolysis produces glycerol and FFA. Furthermore, glycerol is released into culture medium as it cannot be reused directly by the adipocytes. In contrast, only part of the FFA is released into culture medium, because FFA can be re-esterified into triglycerides or consumed via $\beta$-oxidation in the adipocytes, depending on the different states 
of the cells (35). Thus, the glycerol content, rather than FFA content, in the incubation medium is used as an ideal index for lipolysis. The present result suggested that BBR induced lipolysis in a dose- and time-dependent manner in porcine adipocytes, and no cell toxicity was detected, thus indicating that BBR can effectively increase mobilization of TG from porcine WAT.

The cAMP-dependent PKA pathway mediates hormone-stimulated lipolysis in adipocytes. In response to stimulation of catecholamine hormones and other agonists, intracellular cAMP production elevates and activates PKA, which subsequently activates HSL and promotes HSL translocation from the cytosol to lipid droplets, thus facilitating hydrolysis of TG (36). In the present study, it was found that BBR did not increase cAMP content in porcine adipocytes. Furthermore, the PKA inhibitor H89 did not block BBR-induced lipolysis, suggesting that BBR-induced lipolysis is independent of the cAMP/PKA pathway and that this lipolytic action occurs in the basal state.

Terminal regulation of lipolysis in adipocytes mainly involves Perilipin A and two rate-limiting enzymes, ATGL and HSL. Furthermore, ATGL catalyzes the hydrolysis of TG to diglyceride (DG) and FFA, and HSL is mainly responsible for hydrolysis of DG $(3,4)$. Activation of HSL is associated with phosphorylation/dephosphorylation events, which is regulated by the activities of PKA and AMPK. It has been shown that PKA phosphorylates HSL at Ser563, Ser659 and Ser660, resulting in activation of HSL. In contrast, AMPK phosphorylates HSL at Ser565, which may reduce HSL phosphorylation at the above PKA sites, leading to inactivation of HSL $(14,37,38)$. In the present study, BBR did not elevate HSL phosphorylation at the PKA site, thus suggesting that the cAMP/PKA pathway is not involved in BBR-induced lipolysis.

Phosphorylation of ATGL by AMPK can enhance its lipase activity (19). Moreover, ATGL can also be activated by comparative gene identification 58 (CGI-58) via direct interaction, which is associated with Perilipin A $(39,40)$. In the basal state, CGI-58 combines with Perilipin A, an important protein coating the surface of lipid droplets, which forms a barrier to protect the lipid droplets from lipases, such as ATGL and HSL. When Perilipin A is phosphorylated by PKA or is downregulated, the barrier is broken and lipid droplets are exposed to lipases. Furthermore, CGI-58 is released by Perilipin A to activate ATGL, which leads to increased lipolysis $(36,40,41)$. In the present study, it was demonstrated that BBR decreased the mRNA and protein expression levels of Perilipin A, and increased ATGL phosphorylation, while the expression levels of ATGL and HSL were unchanged. Therefore, the present results indicated that Perilipin A downregulation and ATGL activation contribute to BBR-induced lipolysis, which may involve AMPK activation.

AMPK is considered to be an important sensor of cellular energy homeostasis and is activated upon energy depletion to enhance fat mobilization and FA oxidation for ATP or heat production (17). The present study identified an increase in the phosphorylation of AMPKa in response to BBR treatment. Moreover, the AMPK inhibitor compound C suppressed AMPK $\alpha$ phosphorylation and blocked lipolysis in BBR-treated adipocytes. Moreover, compound $\mathrm{C}$ reversed the inhibitory effect of BBR on the mRNA and protein expression levels of Perilipin A, as well as BBR-stimulated phosphorylation of ATGL. Collectively, the present results provided evidence that AMPK activation mediated BBR-induced lipolysis in porcine adipocytes via the AMPK/Perilipin A/ATGL pathway. Furthermore, the present results were partly in line with results from previous studies in 3T3-L1 adipocytes and mice $(15,19)$. However, a previous study showed that AMPK activation by homocysteine inhibited basal lipolysis in primary murine adipocytes and 3T3-L1 adipocytes (18). This discrepancy between studies may be due to variation in the stage of differentiation of adipocytes.

Lentiviral vectors can produce high viral titers and induce high gene expression in target cells. Moreover, lentiviral vectors can be used for delivery of target genes or siRNAs to terminally differentiated mammalian cells such as adipocytes, myocytes and hepatocytes, using a replication incompetent lentivirus (42). The present results suggested that lentiviral vectors-mediated AMPK $\alpha 1$ shRNA transfection suppressed the mRNA and protein expression levels of AMPK $\alpha 1$ in porcine adipocytes. It was found that the inhibitory rate was $\sim 86 \%$ compared with the control and scrambled shRNA group, thus suggesting that AMPK $\alpha 1$ was efficiently knocked down by the specific shRNA. Therefore, the recombinant lentivirus containing AMPK $\alpha 1$ shRNA could be used to block the AMPK signaling pathway in the subsequent experiments.

Mitochondrial FA oxidation is associated with the density and activity of mitochondria in the cells, which is regulated by a series of related genes. PGC1- $\alpha$ has been shown to be a critical transcriptional regulator in mitochondrial biogenesis and energy metabolism by controlling the expression of its downstream target genes, such as TFAM and nuclear respiratory factor 1 (NRF1), as well as the marker genes related to thermogenesis CPT-1 and UCP2 (43-45). Moreover, TFAM and NRF1 act as two key transcription factors that activate mitochondrial DNA transcription and replication synergistically, thus resulting in increased mitochondrial content and enhanced mitochondrial respiratory function $(46,47)$. CPT-1, a rate-limiting enzyme of FA oxidation, functions as a 'shuttle' to deliver long-chain FA from the cytoplasm into mitochondria for $\beta$-oxidation (48). UCP2 is thought to drive uncoupling of oxidative phosphorylation from the mitochondrial respiratory chain, leading to elevated energy expenditure by heat production in adipocytes (49). In the present study, it was demonstrated that BBR treatment increased mRNA expression levels of PGC-1 $\alpha$, TFAM, CPT-1 and UCP2, which paralleled alterations to the protein expression levels. In addition, the present results suggested that knockdown of AMPK $\alpha 1$ in porcine adipocytes significantly reversed BBR-stimulated upregulation of the above genes. Thus, the present results indicated that BBR promoted mitochondrial FA oxidation and thermogenesis in porcine adipocytes by activating the AMPK/PGC-1 $\alpha$ pathway, which may contribute to the maintenance and enhancement of BBR-induced lipolysis at least in part due to decreased FFA accumulation. Moreover, the present results are consistent with previous results in murine adipose tissue (44). However, this effect requires further investigation using FFA radioactive labeling, which will be carried out in future studies.

Mild mitochondrial uncoupling can induce ATGL/HSLindependent lipolysis, which relies on a form of autophagy in 3T3-L1 adipocytes (50). Whether BBR-induced lipolysis 
involves this pathway is not fully understood. However, a previous conflicting study revealed that AMPK has a suppressive effect on FA oxidation and energy utilization within adipose tissue (19). The discrepancy between studies may be attributed to the differential physiological status of the adipocytes.

Insulin signaling plays vital regulatory roles in energy metabolism and health status (51). It has been shown that serine phosphorylation of IRS proteins impairs insulin signaling, which is a mechanism shared by several inducers of insulin resistance including inflammatory cytokines and FFA $(51,52)$. Mitochondrial FA oxidation helps alleviate the inhibitory effect of FFA on insulin signaling in adipocytes (45). In the present study, treatment with TNF $\alpha$, a known inflammatory cytokine and lipolytic inducer, enhanced serine phosphorylation of IRS-1 in porcine adipocytes. However, BBR treatment did not alter IRS-1 serine phosphorylation, thus indicating that BBR and BBR-induced lipolysis does not block insulin signaling at IRS-1 level. Therefore, the present results suggested that enhanced FA oxidation may accompany BBR-induced lipolysis to decrease FFA accumulation.

In conclusion, the present results indicated that BBR induced basal lipolysis in porcine adipocytes via multiple AMPK-dependent mechanisms. Moreover, this lipolytic process did not block insulin signaling at the IRS-1 level. Therefore, the present study provides novel evidence that BBR is a beneficial lipolytic inducer, and may provide potenital molecular targets for the reduction of porcine body fat. Furthermore, BBR may be used to facilitate the development of prevention and treatment strategies for human obesity and insulin resistance.

\section{Acknowledgements}

The authors would like to thank Dr Bin Wu (Arizona Center for Reproduction, USA) and Dr Shupei Wang (University of Montreal, Canada) for their helpful suggestions and corrections of the English manuscript.

\section{Funding}

The present study was supported by the National Natural Science Foundation of China (grant no. 30972091), the Program for Top Young Academic Leaders of Higher Learning Institutions of Shanxi (grant no. 201004) and the Project of 131 Leading Talent of Higher Learning Institutions of Shanxi (grant no. 2013209).

\section{Availability of data and materials}

All data generated and/or analyzed during the present study are included in this published article.

\section{Authors' contributions}

YY and RL conceived and designed the experiments. YY, RL, FG, JZ and FL performed the experiments. FG, JZ and FL analyzed and interpreted the data. YY, RL and FG wrote the manuscript. All authors read and approved the final manuscript.

\section{Ethics approval and consent to participate}

All experimental procedures involving animals were strictly carried out according to The Guide for the Care and Use of Laboratory Animals and were approved by The Institutional Ethics Committee of Shanxi Normal University.

\section{Patient consent for publication}

Not applicable.

\section{Competing interests}

The authors declare that they have no competing interests.

\section{References}

1. Rosen ED and Spiegelman BM: Adipocytes as regulators of energy balance and glucose homeostasis. Nature 444: 847-853, 2006.

2. Gunawardana SC: Benefits of healthy adipose tissue in the treatment of diabetes. World J Diabetes 5: 420-430, 2014.

3. Eichmann TO, Kumari M,Haas JT, Farese RV Jr,Zimmermann R, Lass A and Zechner R: Studies on the substrate and stereo/regioselectivity of adipose triglyceride lipase, hormone-sensitive lipase, and diacylglycerol-O-acyltransferases. J Biol Chem 287: 41446-41457, 2012.

4. Haemmerle G, Zimmermann R, Hayn M, Theussl C, Waeg G, Wagner E, Sattler W, Magin TM, Wagner EF and Zechner R: Hormone-sensitive lipase deficiency in mice causes diglyceride accumulation in adipose tissue, muscle, and testis. J Biol Chem 277: 4806-4815, 2002.

5. Wang SP, Yang H, Wu JW, Gauthier N, Fukao T and Mitchell GA: Metabolism as a tool for understanding human brain evolution: Lipid energy metabolism as an example. J Hum Evol 77: 41-49, 2014.

6. Boden G: Effects of free fatty acids (FFA) on glucose metabolism: Significance for insulin resistance and type 2 diabetes. Exp Clin Endocrinol Diabetes 111: 121-124, 2003.

7. Hauke S, Keutler K, Phapale P, Yushchenko DA and Schultz C: Endogenous fatty acids are essential signaling factors of pancreatic $\beta$-cells and insulin secretion. Diabetes 67: 1986-1998, 2018.

8. Xin Y, Wang Y, Chi J, Zhu X, Zhao H, Zhao S and Wang Y: Elevated free fatty acid level is associated with insulin-resistant state in nondiabetic Chinese people. Diabetes Metab Syndr Obes 12: 139-147, 2019.

9. Kashyap S, Belfort R, Gastaldelli A, Pratipanawatr T, Berria R, Pratipanawatr W, Bajaj M, Mandarino L, DeFronzo R and Cusi K: A sustained increase in plasma free fatty acids impairs insulin secretion in nondiabetic subjects genetically predisposed to develop type 2 diabetes. Diabetes 52: 2461-2474, 2003.

10. Jin Y, Khadka DB and Cho WJ: Pharmacological effects of berberine and its derivatives: A patent update. Expert Opin Ther Pat 26: 229-243, 2016.

11. Choi JS, Kim JH, Ali MY, Min BS, Kim GD and Jung HA: Coptis chinensis alkaloids exert anti-adipogenic activity on 3T3-L1 adipocytes by downregulating C/EBP- $\alpha$ and PPAR- $\gamma$. Fitoterapia 98: 199-208, 2014.

12. Li Y, Zhao X, Feng X, Liu X, Deng $\mathrm{C}$ and $\mathrm{Hu} \mathrm{CH}$ : Berberine alleviates olanzapine-induced adipogenesis via the AMPK $\alpha$-SREBP pathway in 3T3-L1 cells. Int J Mol Sci 17: E1865, 2016.

13. Wang C, Wang Y, Ma SR, Zuo ZY, Wu YB, Kong WJ, Wang AP and Jiang JD: Berberine inhibits adipocyte differentiation, proliferation and adiposity through down-regulating galectin-3. Sci Rep 9: 13415, 2019.

14. Zhou L, Wang X, Yang Y, Wu L, Li F, Zhang R, Yuan G, Wang N, Chen $M$ and Ning G: Berberine attenuates cAMP-induced lipolysis via reducing the inhibition of phosphodiesterase in 3T3-L1 adipocytes. Biochim Biophys Acta 1812: 527-535, 2011.

15. Jiang D, Wang D, Zhuang X, Wang Z, Ni Y, Chen S and Sun F: Berberine increases adipose triglyceride lipase in 3T3-L1 adipocytes through the AMPK pathway. Lipids Health Dis 15: 214,2016 
16. Carling D: The AMP-activated protein kinase cascade-a unifying system for energy control. Trends Biochem Sci 29: 18-24, 2004.

17. Li J, Li S, Wang F and Xin F: Structural and biochemical insights into the allosteric activation mechanism of AMP-activated protein kinase. Chem Biol Drug Des 89: 663-669, 2017.

18. Wang Z, Pini M, Yao T, Zhou Z, Sun C, Fantuzzi G and Song Z: Homocysteine suppresses lipolysis in adipocytes by activating the AMPK pathway. Am J Physiol Endocrinol Metab 301: E703-E712, 2011.

19. Kim SJ, Tang T, Abbott M, Viscarra JA, Wang Y and Sul HS: AMPK phosphorylates desnutrin/ATGL and hormone-sensitive lipase to regulate lipolysis and fatty acid oxidation within adipose tissue. Mol Cell Biol 36: 1961-1976, 2016

20. Koopmans SJ and Schuurman T: Considerations on pig models for appetite, metabolic syndrome and obese type 2 diabetes: From food intake to metabolic disease. Eur J Pharmacol 759: 231-239, 2015

21. Hausman GJ, Basu U, Wei S, Hausman DB and Dodson MV: Preadipocyte and adipose tissue differentiation in meat animals: Influence of species and anatomical location. Annu Rev Anim Biosci 2: 323-351, 2014

22. Yang Y and Yang G: Rosiglitazone regulates IL-6-stimulated lipolysis in porcine adipocytes. Biochem Cell Biol 88: 853-860, 2010.

23. Bai L, Pang WJ, Yang YJ and Yang GS: Modulation of Sirt1 by resveratrol and nicotinamide alters proliferation and differentiation of pig preadipocytes. Mol Cell Biochem 307: 129-140, 2008.

24. Livak KJ and Schmittgen TD: Analysis of relative gene expression data using real-time quantitative PCR and the 2(-Delta Delta C(T)) Method. Methods 25: 402-408, 2001.

25. Ding L, Zhang F, Zhao MX, Ren XS, Chen Q, Li YH Kang YM and Zhu GQ: Reduced lipolysis response to adipose afferent reflex involved in impaired activation of adrenoceptor-cAMP-PKA-hormone sensitive lipase pathway in obesity. Sci Rep 6: 34374, 2016.

26. Yang Y, Liu F, Lu R and Jia J: Berberine inhibits adipogenesis in porcine adipocytes via AMP-Activated protein kinase-dependent and -independent mechanisms. Lipids 54: 667-678, 2019.

27. YangY, Ju D, Zhang M and Yang G: Interleukin-6stimulates lipolysis in porcine adipocytes. Endocrine 33: 261-269, 2008.

28. Capurso $C$ and Capurso A: From excess adiposity to insulin resistance: The role of free fatty acids. Vascul Pharmacol 57: 91-97, 2012.

29. Chen C, Yu Z, Li Y, Fichna J and Storr M: Effects of berberine in the gastrointestinal tract - a review of actions and therapeutic implications. Am J Chin Med 42: 1053-1070, 2014.

30. Xu JH, Liu XZ, Pan W and Zou DJ: Berberine protects against diet-induced obesity through regulating metabolic endotoxemia and gut hormone levels. Mol Med Rep 15: 2765-2787, 2017.

31. Ye L, Liang S, Guo C, Yu X, Zhao J, Zhang H and Shang W: Inhibition of M1 macrophage activation in adipose tissue by berberine improves insulin resistance. Life Sci 166: 82-91, 2016.

32. Zhang X, Zhao Y, Zhang M, Pang X, Xu J, Kang C, Li M, Zhang C, Zhang Z, Zhang Y, et al: Structural changes of gut microbiota during berberine-mediated prevention of obesity and insulin resistance in high-fat diet-fed rats. PLoS One 7: e42529, 2012.

33. Barazzoni R, Gortan Cappellari G, Ragni M and Nisoli E: Insulin resistance in obesity: An overview of fundamental alterations. Eat Weight Disord 23: 149-157, 2018.

34. Ribas V, Nguyen MT, Henstridge DC, Nguyen AK, Beaven SW, Watt MJ and Hevener AL: Impaired oxidative metabolism and inflammation are associated with insulin resistance in ERalpha-deficient mice. Am J Physiol Endocrinol Metab 298 E304-E319, 2010

35. Zambell KL, Horn WF and Keim NL: Conjugated linoleic acid supplementation in humans: Effects on fatty acid and glycerol kinetics. Lipids 36: 767-772, 2001.

36. Miyoshi H, Souza SC, Zhang HH, Strissel KJ, Christoffolete MA, Kovsan J, Rudich A, Kraemer FB, Bianco AC, Obin MS, et al: Perilipin promotes hormone-sensitive lipase-mediated adipocyte lipolysis via phosphorylation-dependent and -independent mechanisms. J Biol Chem 281: 15837-15844, 2006.
37. Smith AJ, Thompson BR, Sanders MA and Bernlohr DA: Interaction of the adipocyte fatty acid-binding protein with the hormone-sensitive lipase: Regulation by fatty acids and phosphorylation. J Biol Chem 282: 32424-32432, 2007.

38. Jocken JW, Roepstorff C, Goossens GH, van der Baan P, van Baak M, Saris WH, Kiens B and Blaak EE: Hormone-sensitive lipase serine phosphorylation and glycerol exchange across skeletal muscle in lean and obese subjects: Effect of beta-adrenergic stimulation. Diabetes 57: 1834-1841, 2008.

39. Lass A, Zimmermann R, Haemmerle G, Riederer M, Schoiswohl G, Schweiger M, Kienesberger P, Strauss JG, Gorkiewicz G and Zechner R: Adipose triglyceride lipase-mediated lipolysis of cellular fat stores is activated by CGI-58 and defective in Chanarin-Dorfman Syndrome. Cell Metab 3: 309-319, 2006

40. Subramanian V, Rothenberg A, Gomez C, Cohen AW, Garcia A Bhattacharyya S, Shapiro L, Dolios G, Wang R, Lisanti MP, et al: Perilipin A mediates the reversible binding of CGI-58 to lipid droplets in 3T3-L1 adipocytes. J Biol Chem 279: 42062-42071, 2004.

41. Sahu-Osen A, Montero-Moran G, Schittmayer M, Fritz K, Dinh A, Chang YF, McMahon D, Boeszoermenyi A, Cornaciu I, Russell D, et al: CGI-58/ABHD5 is phosphorylated on Ser239 by protein kinase A: Control of subcellular localization. J Lipid Res 56: 109-121, 2015.

42. Durand S and Cimarelli A: The inside out of lentiviral vectors. Viruses 3: 132-159, 2011.

43. Yan Y, Yang X, Zhao T, Zou Y, Li R and Xu Y: Salicylates promote mitochondrial biogenesis by regulating the expression of PGC-1 $\alpha$ in murine 3T3-L1 pre-adipocytes. Biochem Biophys Res Commun 491: 436-441, 2017.

44. Yan M, Audet-Walsh É, Manteghi S, Dufour CR, Walker B, Baba M, St-Pierre J, Giguère V and Pause A: Chronic AMPK activation via loss of FLCN induces functional beige adipose tissue through PGC-1 $\alpha /$ ERR $\alpha$. Genes Dev 30: 1034-1046, 2016.

45. Kleiner S, Mepani RJ, Laznik D, Ye L, Jurczak MJ, Jornayvaz FR, Estall JL, Chatterjee Bhowmick D, Shulman GI and Spiegelman BM: Development of insulin resistance in mice lacking PGC-1 $\alpha$ in adipose tissues. Proc Natl Acad Sci USA 109: 9635-9640, 2012.

46. Scarpulla RC: Transcriptional paradigms in mammalian mitochondrial biogenesis and function. Physiol Rev 88: 611-638, 2008.

47. Chen Z, Tao S, Li X and Yao Q: Resistin destroys mitochondrial biogenesis by inhibiting the PGC-1 $\alpha$ / NRF1/TFAM signaling pathway. Biochem Biophys Res Commun 504: 13-18, 2018.

48. Calderon-Dominguez M, Sebastián D, Fucho R, Weber M, Mir JF, García-Casarrubios E, Obregón MJ, Zorzano A, Valverde ÁM, Serra D, et al: Carnitine palmitoyltransferase 1 increases lipolysis, UCP1 protein expression and mitochondrial activity in brown adipocytes. PLoS One 11: e0159399, 2016.

49. Jia JJ, Zhang X, Ge CR and Jois M: The polymorphisms of UCP2 and UCP3 genes associated with fat metabolism, obesity and diabetes. Obes Rev 10: 519-526, 2009.

50. Demine S, Tejerina S, Bihin B, Thiry M, Reddy N, Renard P, Raes M, Jadot M and Arnould T: Mild mitochondrial uncoupling induces HSL/ATGL-independent lipolysis relying on a form of autophagy in 3T3-L1 adipocytes. J Cell Physiol 233: 1247-1265, 2018.

51. Hotamisligil GS: Inflammation and metabolic disorders. Nature 444: 860-867, 2006.

52. Tanti JF and Jager J: Cellular mechanisms of insulin resistance: Role of stress-regulated serine kinases and insulin receptor substrates (IRS) serine phosphorylation. Curr Opin Pharmacol 9: 753-762, 2009. 